\title{
Evaluation of the merit of the methanolic extract of Andrographis paniculata to supplement anti-snake venom in reversing secondary hemostatic abnormalities induced by Naja naja venom
}

\author{
Akshatha Ganesh Nayak $^{1}$ (D) Nitesh Kumar ${ }^{2}$ (D) $\cdot$ Smita Shenoy $^{3}$ (D) Maya Roche $^{1}$ (D)
}

Received: 24 February 2021 / Accepted: 29 March 2021 / Published online: 21 April 2021

(c) The Author(s) 2021

\begin{abstract}
Increasing evidence suggests a sizable involvement of hemotoxins in the morbidity associated with envenomation by the Indian spectacled cobra, Naja naja (N.N). This study investigates the ability of Indian polyvalent anti-snake venom (ASV), methanolic extract of Andrographis paniculata (MAP) and their combination in reversing the hemostatic abnormalities, viz. activated partial thromboplastin time(aPTT), prothrombin time(PT) and thrombin time(TT) in citrated plasma. These parameters were assessed in 2 groups of experiments. Group 1: Without the prior incubation of plasma with venom and Group 2: With prior incubation of plasma with venom for $90 \mathrm{~min}$ at $37^{\circ} \mathrm{C}$. Venom caused significant $(p<0.001)$ prolongation in aPTT (175\%), PT (49\%) and TT (34\%) in Group 1 and ASV could completely bring them back to normal. MAP showed a concentration-dependent reversal in aPTT, normalization of PT and prolongation of TT. When low concentration of ASV was supplemented with MAP, their combined effect in normalizing aPTT and PT improved by $37 \%$ and $26 \%$ respectively when compared to ASV alone. In Group 2, venom caused significant $(p<0.001)$ prolongation in aPTT $(231 \%)$, PT (312\%) and TT $(245 \%)$. ASV had limited effect in reversing aPTT (52\%), TT (31\%) but completely normalized PT. MAP was marginally effective in reversing the prolonged aPTT and PT but caused further prolongation of TT. Combination of ASV and MAP was more effective than ASV alone in reversing venom-induced increase in aPTT (52\%) and PT (29\%). The study proved that, a drastic reduction of ASV by 70\%, could be effectively supplemented by MAP in combating hemostatic abnormalities induced by $\mathrm{NN}$ venom.
\end{abstract}

Keywords Activated partial thromboplastin time $\cdot$ Hemostatic $\cdot$ Methanolic extract of Andrographis paniculata $\cdot$ Naja naja $\cdot$ Prothrombin time $\cdot$ Supplement $\cdot$ Thrombin time

Maya Roche

maya.roche@manipal.edu

Akshatha Ganesh Nayak

akshatha.pai@manipal.edu

Nitesh Kumar

niteshkumar43@gmail.com

Smita Shenoy

smita.shenoy@manipal.edu

1 Department of Biochemistry, Melaka Manipal Medical College (Manipal Campus), Manipal Academy of Higher Education, Manipal, Karnataka, India

2 Department of Pharmacology and Toxicology, National Institute of Pharmaceutical Education and Research (NIPER), Hajipur, Bihar, India

3 Department of Pharmacology, Kasturba Medical College, Manipal Academy of Higher Education, Manipal, Karnataka, India

\section{Introduction}

The venom of the Indian spectacled cobra, Naja naja (N.N) is a cocktail of 81 different toxins (Choudhury et al., 2017). The venom is generally known to be neurotoxic due to the presence of multiple neurotoxins with different mechanisms of action (Paoli et al., 2009; Barber, Isbister and Hodgson, 2013; Ranawaka, Lalloo and de Silva, 2013; Urs et al., 2014). These cause systemic paralysis of muscles, including those involved in respiration, leading to death (Ahmed et al., 2008). Increasing evidence suggests a sizable involvement of hemotoxins in the morbidity associated with N.N bite, causing wide-spread changes in hemostasis. These effects are mediated by toxins that affect platelet aggregation (Kumar et al., 2010), coagulation (Berling and Isbister, 2015), hemolysis (Dissanayake et al., 2018) and fibrinogenolysis (Gowda et al., 2006; Kumar et al., 2010). 
The venom of N.N is primarily anticoagulant. The 5'-nucleotidase and $\mathrm{NnPLA}_{2}$-I, a phospholipase with molecular weight of $15.2 \mathrm{KDa}$, are known to cause an anticoagulant effect (Dhananjaya et al., 2006; Dutta, Gogoi and Mukherjee, 2015). There are conflicting reports regarding the ability of the venom to prolong the prothrombin time (Gowda et al., 2006; Gowtham et al., 2012). The venom is also known to prolong the re-calcification time (Gowda et al., 2006), activated partial thromboplastin time (aPTT) and thrombin time (TT) (Gowtham et al., 2012). Though the venom promotes clot formation in-vitro, by activating prothrombin, the clots formed are abnormally low in elasticity due to decreased clot retraction (Sundell et al., 2003). N.N venom hydrolyses the $\alpha$-chain of fibrinogen (Gowda et al., 2006) and shows feeble plasmin-like activity on fibrin clot (Gowtham et al., 2012). NN-PF3, a metalloprotease from N.N venom with molecular mass $67.81 \mathrm{KDa}$, prolonged aPTT, PT, TT, exhibited fibrin(ogen)olytic activity which was inhibited by polyvalent anti-snake venom (ASV). It did not affect the activity of thrombin. It inhibited platelet aggregation primarily by affecting $\alpha_{2} \beta_{1}$ integrin (Kumar et al., 2011). Crude N.N venom and purified NND-IV-PLA ${ }_{2}$ from the venom, inhibited ADP and epinephrine-induced platelet aggregation (Gowtham et al., 2012, Satish et al., 2004). Widespread changes affecting different stages of clotting such as R- time, K-time, angle, amplitude and fibrin(ogen) olysis were well documented in real-time using thromboelastography (TEG). These changes were completely reversed by ASV and the methanolic extract of Andrographis paniculata (MAP) when used individually or in combination (Nayak, Ahammad, et al., 2020).

In India, the only available antidote to envenomation with N.N is a polyvalent ASV which claims to neutralize the venoms of the four predominant snake species of the subcontinent, i.e., Daboia russelli, Bungarus caeruleus, Echis carinatus and Naja naja. Though the ASV is effective in saving lives, its use has many limitations. It is administered to envenomed patients with extreme caution, only when initial evidence of neurotoxicity manifesting as ptosis of the eyes is observed. By that time, the venom would have spread systemically, causing a number of hemostatic changes as mentioned above. One of the manifestations of the hemostatic abnormalities is the hemorrhage (Suvilesh et al., 2017) that occurs at the bite site. The ASV is also known to cause a number of adverse reactions including itching, urticaria, dry cough, nausea, vomiting, diarrhea, tachycardia, fever, etc. (Ahmed et al., 2008; Deshpande et al., 2013; De Silva, Ryan and De Silva, 2016). In addition, it does not address the local effects of the venom such as bleeding, edema, pain etc. (Rucavado, Escalante and Gutiérrez, 2004; Girish and Kemparaju, 2005). Agricultural labourers in India, who are the common targets of N.N bites have poor access to ASV and can ill-afford this expensive treatment. It is well documented that higher doses of ASV are associated with higher incidences of adverse reactions including anaphylaxis (Chube et al., 2016). Any treatment modality that could reduce the dosage of ASV given to the patient would prove beneficial in not only mitigating the adverse reactions but also reduce the cost of treatment. The present study explores such a possibility of supplementation of low concentrations of ASV with a herbal extract.

The methanolic extract of Andrographis paniculata (MAP) has shown a number of beneficial effects in counteracting N.N venom toxicity. MAP from leaves and roots, when studied in-vitro against N.N venom has shown neutralizing properties against phosphomonoesterase, phosphodiesterase, acetylcholinesterase, phospholipase $\mathrm{A}_{2}$, hyaluronidase, L-amino acid oxidase, ATPase and fibrinolytic activities (Gopi et al., 2011; R S A, P C and Gnaniah, 2014; Sivakumar A, Manikandan A, 2015; Mani, 2015). The extract was capable of reducing edema (R S A, P C and Gnaniah, 2014; Rajesh et al., 2017) and hemorrhage (Alam, 2014) in-vivo and also prolonged the survival time in mice (Premendran et al. 2011). In the light of encouraging findings obtained with TEG (Nayak, Ahammad, et al., 2020) and inhibition of venom acetylcholinesterase (AchE) and hyaluronidase (Nayak, Kumar, et al., 2020) by a combination of ASV and MAP, it was thought worthwhile to explore the effects of this combined strategy on secondary hemostasis which involves the extrinsic, intrinsic and common pathways of clotting.

\section{Materials and methods}

\section{Ethical clearance.}

The present study was conducted after obtaining the clearance from Institutional Ethics Committee (IEC: 320/2017), Kasturba Medical College, Manipal Academy of Higher Education, Manipal, Karnataka, India.

\section{Blood Samples}

Whole blood samples were collected from healthy volunteers using citrated vacutainers, after obtaining their consent to participate in the study. Plasma was separated and used for immediate estimations of PT, aPTT and TT.

\section{Naja naja (N.N) venom}

Lyophilized form of N.N venom was procured from K.V Institute, Sagarpalli District, Ballia, Uttar Pradesh (License No. $01 /$ Snake $1 / 2004-05$ ) and stored at $2-8^{\circ} \mathrm{C}$. Venom stock solution was prepared by dissolving $10 \mathrm{mg}$ in $1 \mathrm{ml}$ of $0.08 \mathrm{M}$ phosphate buffer ( $\mathrm{pH} 7.6$ ), stored at $2-8^{\circ} \mathrm{C}$ until further use. Aliquots of working venom solutions were prepared using 
the same buffer. It was observed that N.N venom at $3 \mu \mathrm{g}$, caused a measurable change in aPTT and so this concentration was selected for further use. In the case of PT and TT, a higher concentration was required to enable the appearance of a clot and so these experiments were carried out using $10 \mu \mathrm{g}$ N.N venom.

\section{Anti-snake venom (ASV)}

Polyvalent ASV was obtained from Bharat Serums and Vaccines Pvt. Ltd, Ambarnath, Maharashtra, India. Contents of the entire vial were reconstituted using $10 \mathrm{ml}$ sterile water provided by the manufacturer and stored at $2-8^{\circ} \mathrm{C}$. According to the manufacturer, $1 \mathrm{ml}$ of reconstituted ASV could neutralize $0.6 \mathrm{mg}$ of N.N venom and contained $2.2 \mathrm{mg}$ protein by Lowry's method (Randall and Lewis, 1951). For the estimation of PT, aPTT and TT, aliquots of reconstituted ASV were used in the range of $5 \mu \mathrm{l}-17 \mu \mathrm{l}$ containing $11 \mu \mathrm{g}-37.4 \mu \mathrm{g}$ protein by Lowry's method.

\section{Methanolic extract of Andrographis paniculata (MAP)}

The MAP was sourced from Natural Remedies Pvt Ltd, Bangalore, Karnataka, India (Batch No. BKCEX/2015Lot010) and stored at $2-8^{\circ} \mathrm{C}$. HPLC and ICP-MS analysis of MAP revealed the presence of andrographolide (31.4\%) and heavy metals such as lead, cadmium, arsenic and mercury in the extract respectively. GC-MS analysis of the methanolic extract showed the presence of 44 compounds whose MS spectra were matched with NIST library for the confirmation of the compounds (Nayak, Ahammad, et al., 2020). Qualitative analysis of MAP revealed the presence of flavonoids, phenols, tannins, terpenoids, carbohydrates and absence of alkaloids. Quantitative analysis of MAP demonstrated the total phenolic content in the extract as $43.55 \mathrm{mg} \mathrm{GAE} / \mathrm{g}$ and total flavonoid content as $11 \mathrm{mg} \mathrm{QE} / \mathrm{g}$ of extract (Nayak, Kumar, et al., 2020).

For the estimation of PT and TT, stock solutions with varying concentrations of MAP were prepared by dissolving $1 \mathrm{mg}, 10 \mathrm{mg}$ and $20 \mathrm{mg}$ in $1 \mathrm{ml}$ dimethyl sulfoxide (DMSO99\% pure). Aliquots from the stock solutions containing $10 \mu \mathrm{g}, 100 \mu \mathrm{g}$ and $200 \mu \mathrm{g}$, respectively, were used in the assays.

For the estimation of aPTT, set of 5 stock solutions of MAP containing $3 \mathrm{mg}, 6 \mathrm{mg}, 12 \mathrm{mg}, 15 \mathrm{mg}$ and $18 \mathrm{mg}$ in $1 \mathrm{ml}$ DMSO were prepared and aliquots containing $30 \mu \mathrm{g}$, $60 \mu \mathrm{g}, 120 \mu \mathrm{g}, 150 \mu \mathrm{g}$ and $180 \mu \mathrm{g}$ were used for the assays based on a pilot study of their effectiveness.

\section{Statistical analysis}

Data was analyzed using SPSS software version 16.0 and comparison of results between the groups was by one-way
ANOVA followed by Tukey's post hoc test. $P<0.05$ was considered as statistically significant. Results were represented in terms of Mean \pm SEM for triplicate samples.

\section{Methodology}

Estimation of aPTT, PT and TT was using commercially available kits.

\section{Estimation of aPTT}

The aPTT was estimated using CoagTHREE kit from AGAPPE (Bain, 2017). For plasma control, citrated plasma $(0.1 \mathrm{ml})$ from healthy volunteers was incubated with $0.1 \mathrm{ml}$ of aPTT reagent and incubated for $3 \mathrm{~min}$ at $37^{\circ} \mathrm{C}$. This was followed by the addition of $0.1 \mathrm{ml}$ of pre-warmed $0.02 \mathrm{M}$ $\mathrm{CaCl}_{2}$ and clotting time was recorded using a timer.

\section{Estimation of PT}

The PT was estimated using CoagTHREE kit from AGAPPE (Bain, 2017). Citrated plasma $(0.1 \mathrm{ml})$ from healthy volunteers was pre-warmed at $37^{\circ} \mathrm{C}$ for $3 \mathrm{~min}$ and $0.2 \mathrm{ml}$ of prewarmed PT reagent was added (plasma control). Clotting time was recorded using a timer.

\section{Estimation of TT}

The thrombin time was estimated using TriniCLOT kit from TCoag (Adcock, Hoefner, Kottke-Marchant, Marlar, 2008). Citrated plasma $(0.2 \mathrm{ml})$ collected from healthy volunteers was pre-warmed for $2 \mathrm{~min}$ at $37^{\circ} \mathrm{C}$ after which $0.1 \mathrm{ml}$ of thrombin reagent was added and time for clot formation was estimated.

All the 3 parameters were assayed in 2 groups of experiments.

In Group I experiments, the aPTT (Fig. 1), PT (Fig. 2) and TT (Fig. 3) were estimated without prior incubation of the plasma with venom. This set of experiments represent the immediate effect of ASV, MAP or their combination on the intrinsic (aPTT), extrinsic (PT) and common pathways (TT) of clotting.

In Group II experiments, the plasma was incubated with venom at $37^{\circ} \mathrm{C}$ for $90 \mathrm{~min}$ following which the aPTT (Fig. 4), PT (Fig. 5), and TT (Fig. 6) were estimated. These experiments represent the effect of ASV, MAP or their combination in reversing the changes in clotting caused by venom constituents over a period of $90 \mathrm{~min}$. These in-vitro experiments simulate the effect the venom on the clotting cascade in a snake bite victim who is brought to the hospital after a period of $90 \mathrm{~min}$ following the bite. A time lapse of $90 \mathrm{~min}$ was selected because in most victims of N.N bite, delay of 
Fig. 1 Effects of ASV, MAP and ASV + MAP on N.N venom-induced changes in aPTT without prior incubation of normal citrated plasma with venom. $A S V$ anti-snake venom; MAP methanolic extract of Andrographis paniculata; N.N Naja naja; aPTT activated partial thromboplastin time

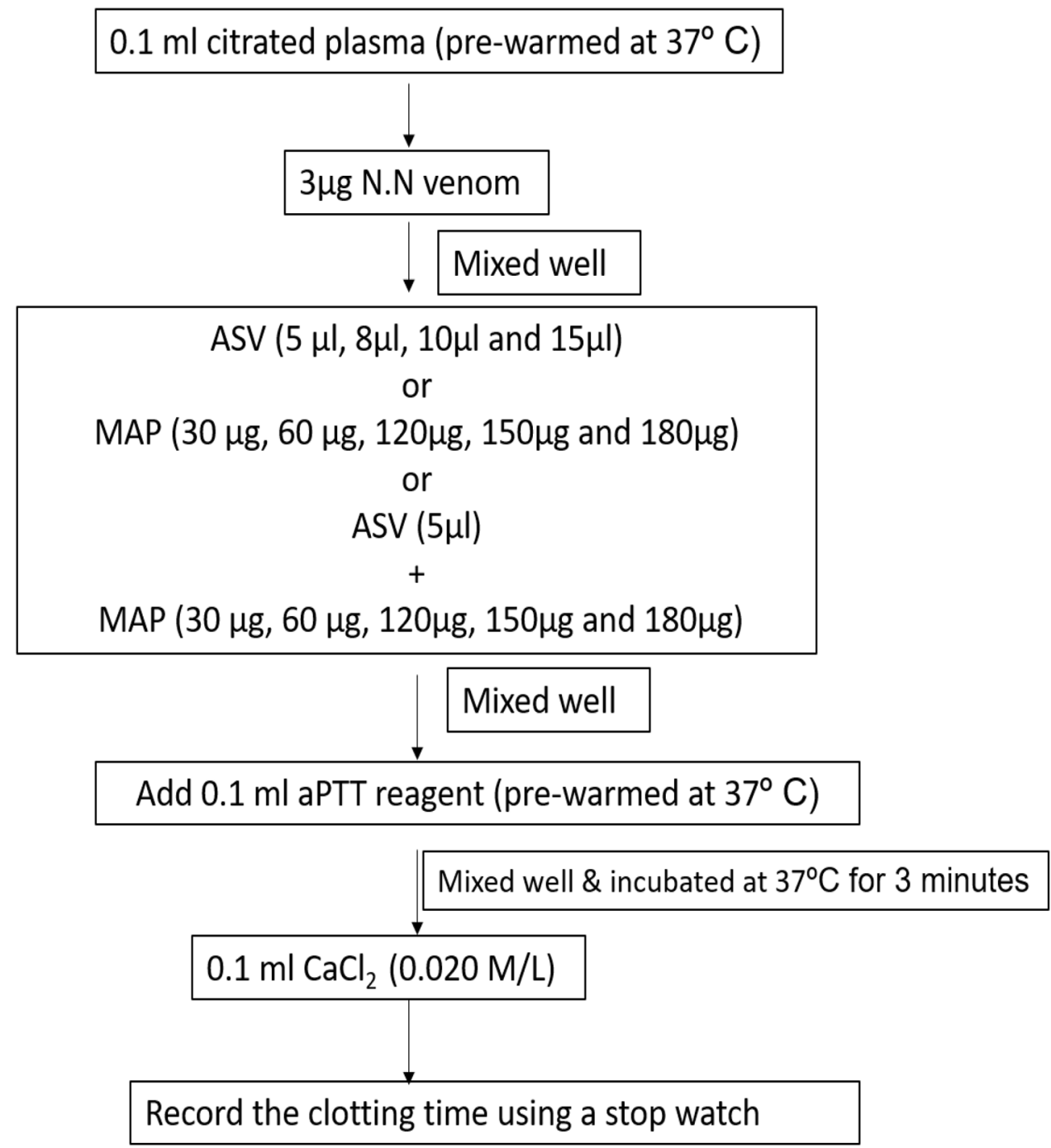

more than 90 min causes death due to respiratory paralysis precluding the possibility of any treatment.

\section{Results}

\section{Group I experiments}

Effect on aPTT Addition of MAP (30-150 $\mu \mathrm{g}$ ) to normal citrated plasma, had no effect on aPTT (normal range: 21-38 s as per CoagTHREE kit). The aPTT of normal citrated plasma was prolonged by $3 \mu \mathrm{g}$ of N.N venom by $175 \%$ under standard assay conditions (Table 1). The ASV in the range of $5 \mu \mathrm{l}$ to $15 \mu \mathrm{l}(11-33 \mu \mathrm{g}$ in terms of Lowry protein) showed a concentration-dependent effect and was able to bring the aPTT back to normal at $15 \mu \mathrm{l}$. The MAP also showed a concentration-dependent effect in the range from 30 to $180 \mu \mathrm{g}$ in bringing the aPTT towards the normal range. When the ASV concentration was minimized to $5 \mu \mathrm{l}$ and supplemented with MAP, aPTT was brought back to normal at MAP concentration of $120 \mu \mathrm{g}$ (Fig. 7). Further increase in MAP concentration up to $180 \mu \mathrm{g}$ caused a prolongation of aPTT.

Effect on PT Addition of MAP (10-200 $\mu \mathrm{g})$ to normal citrated plasma, had no effect on PT (normal range: 10-15 s as per CoagThree kit). N.N venom $(10 \mu \mathrm{g})$ was able to prolong the PT by $49 \%$ (Table 2). Addition of ASV (5 to $17 \mu \mathrm{l}$ ) to a mixture of plasma and venom, showed a concentration-dependent effect in lowering the PT with a complete reversal to normal level at 10 and $17 \mu \mathrm{l}$. MAP also showed a concentration-dependent reversal of PT and brought the PT back to normal at $100 \mu \mathrm{g}$. Further increase of MAP to $200 \mu \mathrm{g}$ prolonged the PT beyond the normal level. When ASV was reduced to $5 \mu$ land supplemented with MAP up to a concentration of $100 \mu \mathrm{g}$, the effect was better $(26 \%)$ than when ASV was used alone (Fig. 8). 
Fig. 2 Effects of ASV, MAP and ASV + MAP on N.N venom-induced changes in PT without prior incubation of normal citrated plasma with venom. $A S V$ anti-snake venom; $M A P$ methanolic extract of Andrographis paniculata; N.N Naja naja; $P T$ prothrombin time

\section{$0.1 \mathrm{ml}$ citrated plasma (pre-warmed at $37^{\circ} \mathrm{C}$ for 3 minutes)}

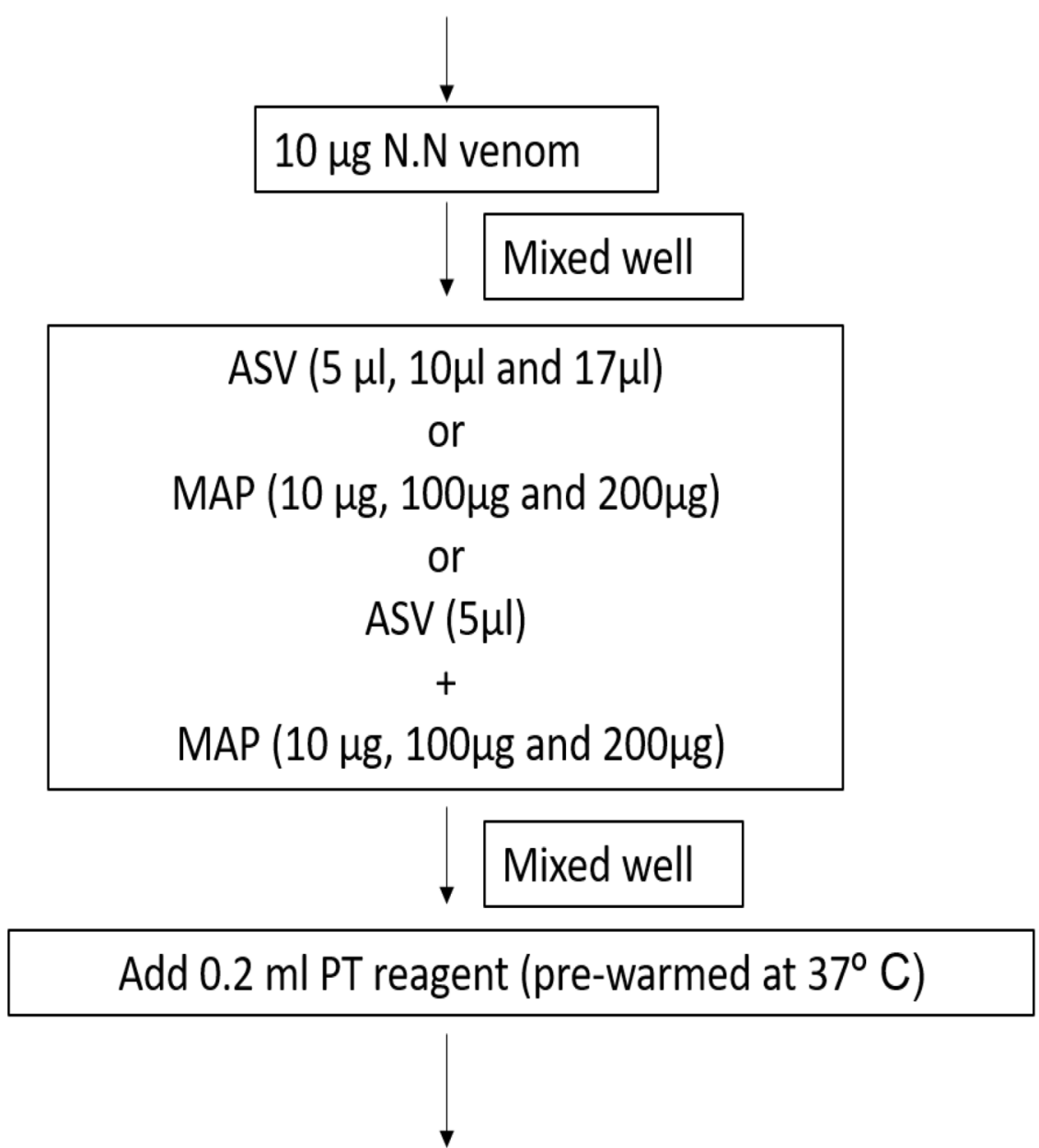

Record the clotting time using a stop watch
Effect on TT Addition of MAP (10-200 $\mu \mathrm{g})$ to normal citrated plasma prolonged the TT by $128-171 \%$. Addition of $10 \mu \mathrm{g}$ of N.N venom to citrated plasma (normal range: $10-15 \mathrm{~s}$ as per TriniCLOT kit) prolonged the TT by $34 \%$ (Table 2). This alteration of TT was completely reversed by the ASV at $17 \mu \mathrm{l}$. Addition of MAP (10-200 $\mu \mathrm{g})$ to normal citrated plasma caused prolongation of TT. Also, in the presence of venom and MAP (10 to $200 \mu \mathrm{g}$ ) the TT was prolonged beyond the normal range. A combination of ASV and MAP was not able to bring TT back to the normal range.

\section{Group 2 experiments}

Effect on aPTT The aPTT was prolonged to a greater extent by $231 \%$ (Table 3 ) when plasma was incubated with the venom for $90 \mathrm{~min}$ prior to the estimation of aPTT. This was $56 \%$ more in comparison to aPTT in Group I experiments.
Addition of ASV 5 to $8 \mu \mathrm{l}$ had a limited effect and reduced the prolonged aPTT by 32 to $52 \%$. Further increase in ASV concentration from 10 to $15 \mu$, prolonged the aPTT, though the aPTT was still shorter by $31-42 \%$ when compared to venom control. MAP was also only partially effective (24$45 \%$ ) in reversing the prolonged aPTT at a concentration of 30 to $60 \mu \mathrm{g}$. Further increase in MAP concentration up to $180 \mu \mathrm{g}$ prolonged the aPTT. Reducing ASV to $5 \mu \mathrm{l}$ and supplementing it with MAP was maximally effective at a MAP concentration of $60 \mu \mathrm{g}$ (Fig. 9), showing a 52\% reduction in aPTT.

Effect on PT Incubation of the plasma with venom for $90 \mathrm{~min}$ at $37^{\circ} \mathrm{C}$, followed by estimation of PT, caused a drastic prolongation of PT to the extent of $312 \%$ (Table 4). ASV was effective in reversing the changes in PT, bringing the PT back to normal at $17 \mu \mathrm{l}$. Effect of MAP (10 to $200 \mu \mathrm{g}$ ) 
Fig. 3 Effects of ASV, MAP and ASV + MAP on N.N venom-induced changes in TT without prior incubation of normal citrated plasma with venom. $A S V$ anti-snake venom; $M A P$ methanolic extract of Andrographis paniculata; N.N Naja naja; TT thrombin time

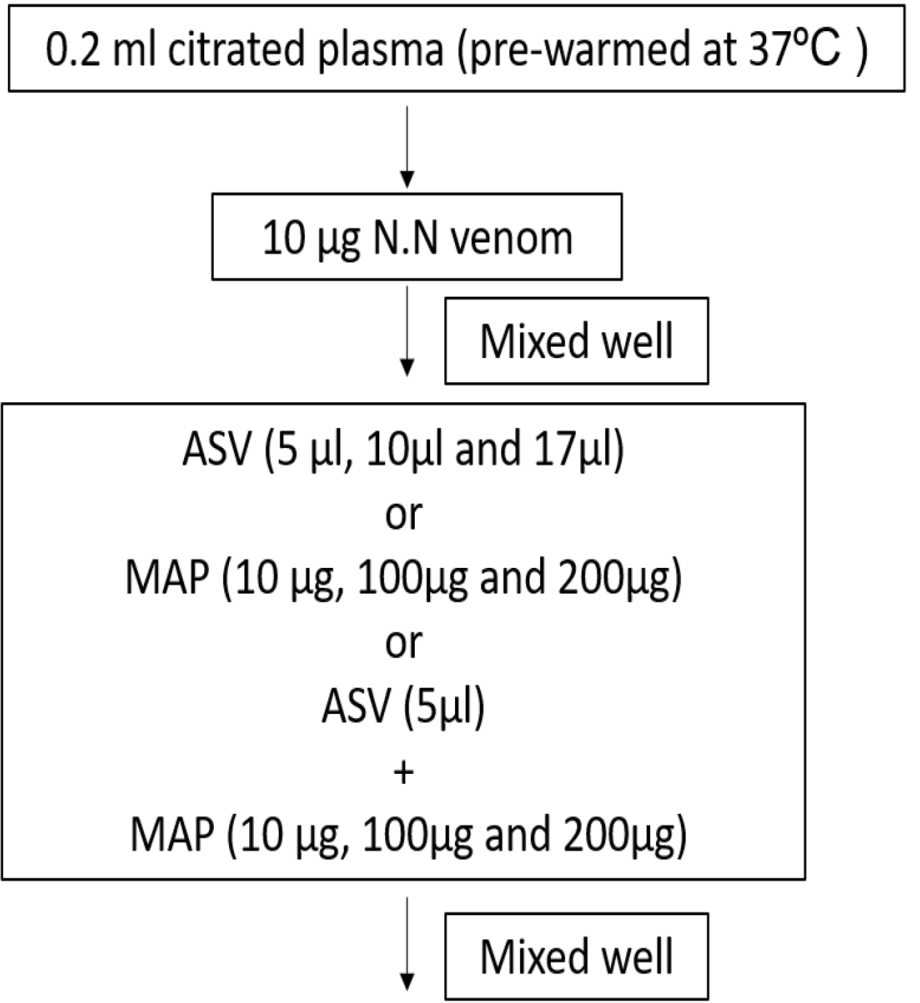

Add $0.1 \mathrm{ml}$ Thrombin reagent (kept at room temperature)

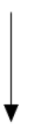

Record the clotting time using a stop watch on the reversal of PT was marginal (only 17\%). When ASV was reduced to $5 \mu \mathrm{l}$ and supplemented with MAP from 10 to $200 \mu \mathrm{g}$, the best effect on PT was observed at ASV $5 \mu$ and MAP $100 \mu \mathrm{g}$ (Fig. 10). Increasing MAP concentration to $200 \mu \mathrm{g}$ did not promote a further decrease in PT.

Effect on TT N.N venom $(10 \mu \mathrm{g})$ prolonged the TT significantly by $245 \%$ (Table 4 ). ASV had a marginal effect (12-31\%) on reversing the TT at a concentration of (5 to $17 \mu \mathrm{l}$ ). MAP prolonged the TT by 18 to $27 \%$ (when compared to venom control). When used in combination with ASV $(5 \mu \mathrm{l})$, MAP showed no significant difference when compared to the use of ASV alone.

\section{Discussion}

As evidenced above, the N.N venom has potent effects on hemostasis. It markedly prolonged the aPTT showing that the intrinsic and common pathways of coagulation involving factor XII, XI, IX, VIII, X, V, II and I is affected. A metalloprotease NN-PF3, from N.N venom with molecular mass $67.81 \mathrm{KDa}$, has been reported to prolong the aPTT and its activity was inhibited by the Indian polyvalent ASV (Kumar et al., 2010). The present study clearly demonstrated the ability of the polyvalent ASV to bring the aPTT back to normal in a concentration-dependent manner. The MAP also was almost as effective as ASV in reversing the changes in aPTT and effectively worked as a supplement in normalizing aPTT in the presence of low ASV concentrations. Plant extracts used in the treatment of bleeding wounds and snake bite are known to contain compounds such as flavonoids, steroids, terpenoids and alkaloids. These constituents are known to have pro-coagulant property (Liang et al., 2019). Such compounds are also found in MAP (Chen et al., 2020). Quercetin, a compound which is also present in MAP (Veeresham et al., 2013) is known to have hemostatic action (Chen et al., 2020). It is evident that the prior incubation of the plasma with venom caused the irreversible destruction of clotting factors of the intrinsic and common pathway as observed 
Fig. 4 Effects of ASV, MAP and ASV + MAP on N.N venom-induced changes in aPTT with prior incubation of normal citrated plasma with venom at $37^{\circ} \mathrm{C}$ for $90 \mathrm{~min}$. $A S V$ anti-snake venom; $M A P$ methanolic extract of Andrographis paniculata; N.N Naja naja; $a P T T$ activated partial thromboplastin time

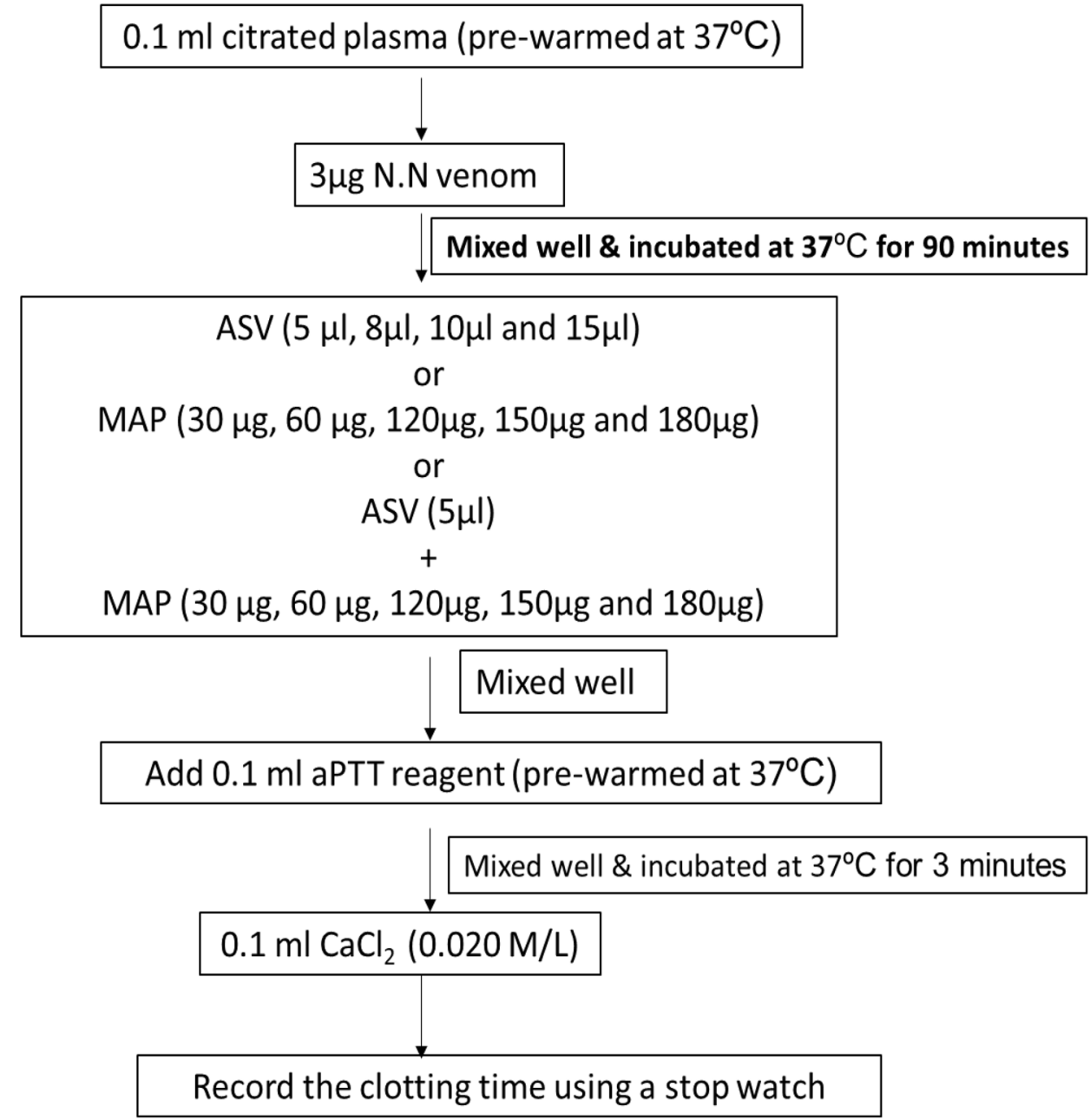

by the prolonged aPTT. Addition of ASV in this condition was relatively less effective and MAP constituents were unable to restore the aPTT to normal. It appears that though they could still bind to venom enzymes, destruction of clotting factors by the venom precluded their action. Similar phenomenon was observed with MAP at higher concentrations of 150 and $180 \mu \mathrm{g}$. MAP contains about more than 90 different organic compounds (Sareer, Ahad, Umar 2012) and at higher concentrations, their access to the active sites of enzymes might become limited due to stearic hindrance (Nayak, Ahammad, et al., 2020). Reducing the concentration of ASV to $5 \mu \mathrm{l}$ and supplementing with MAP $(60-120 \mu \mathrm{g})$ had consistently a superior effect in Group 1 and Group 2 experiments in reducing aPTT, indicating that the ASV and MAP can supplement each other for a better outcome. It should be noted here that the mechanism by which the venom protease interacts with ASV, is different from that of the interaction of the venom proteases with the MAP constituents. The former depends on antigen-antibody interactions whereas the latter is mainly dependent on the binding to the active sites of venom enzymes as demonstrated by in silico experiments (Gopi et al., 2011; Chayamiti, Mwenje and Mahamadi, 2013).

Prothrombin time is a measure of the functioning of the extrinsic and the final common pathways of the coagulation cascade. This consists of tissue factor and factors VII, I (prothrombin) V X, and fibrinogen. The fact that PT was prolonged by the venom to the extent of $49 \%$ and $312 \%$ respectively, without and with prior incubation of the venom with plasma, confirms that the venom contains factors that interfere with the extrinsic pathway of coagulation as also observed by others (Kumar et al., 2010). The finding that ASV was able to reverse the change in PT completely even after exposure of the plasma to venom for $90 \mathrm{~min}$, indicates that the venom enzymes interact with the clotting factors without damaging their function, may be by forming complexes which dissociate on the addition of ASV. Kunitz-type proteinase inhibitors with molecular weight of 6.2 KDa and 6.4 KDa have been isolated from N.N venom (Shafqat, Zaidi and Jörnvall, 1990). These are serine proteinase inhibitors and are capable of binding to serine proteinases (Suvilesh 
Fig. 5 Effect of ASV, MAP and ASV + MAP on N.N venominduced changes in PT with prior incubation of normal citrated plasma with venom at $37^{\circ} \mathrm{C}$ for $90 \mathrm{~min} . A S V$ anti-snake venom; MAP methanolic extract of Andrographis paniculata; N.N Naja naja; PT prothrombin time

\section{$0.1 \mathrm{ml}$ citrated plasma (pre-warmed at $37^{\circ} \mathrm{C}$ for 3 minutes)}

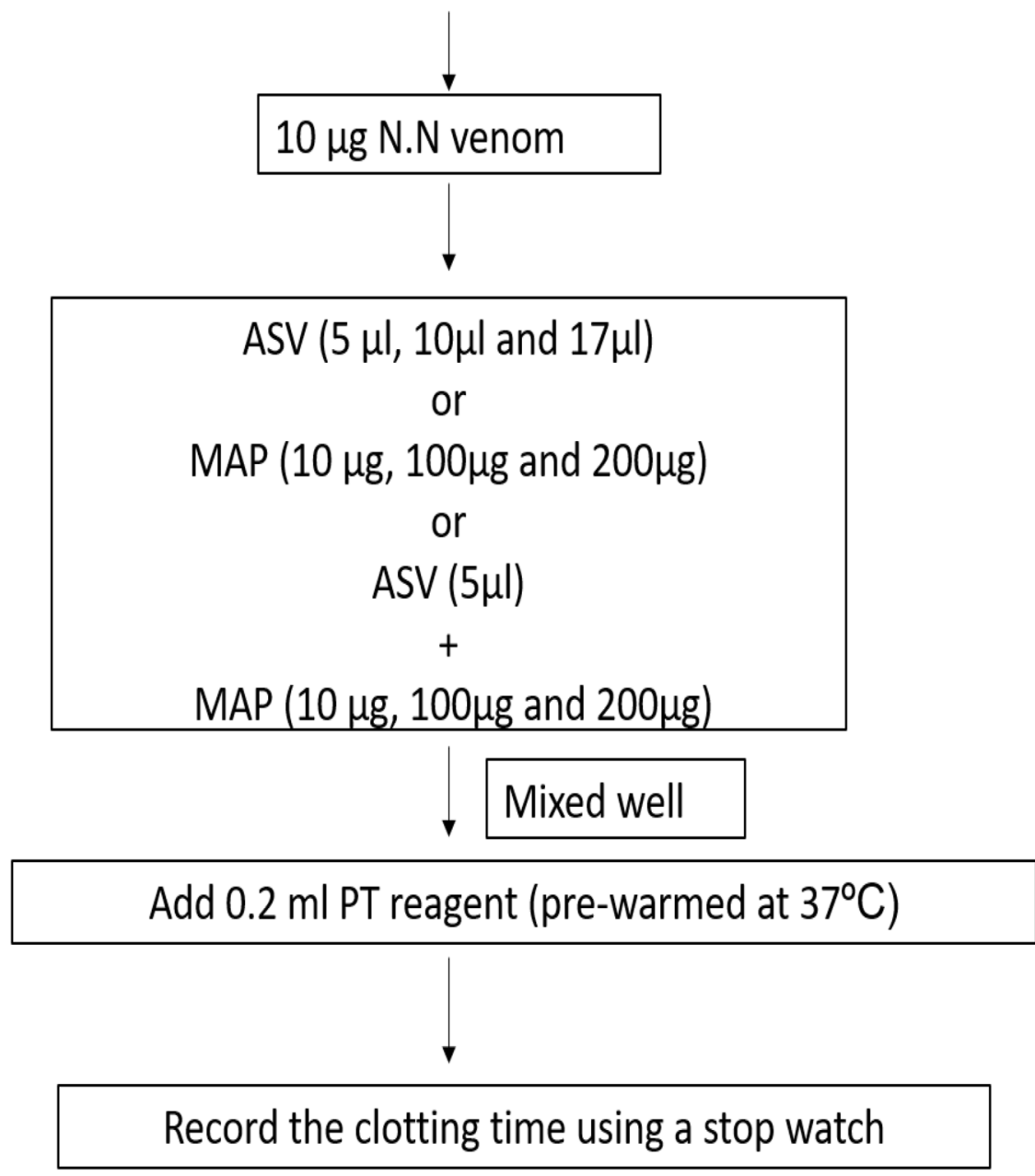

et al. 2017) of the clotting cascade such as factor VIIa, $\mathrm{Xa}$, IIa, possibly prolonging PT. NN-PF3, a metalloprotease from NN venom with molecular mass $67.81 \mathrm{KDa}$, has fibrin(ogen)olytic activity (Kumar et al., 2010) and has been shown to prolong PT but does not prevent clotting. This enzyme cleaves the $\alpha$-chain of fibrinogen and the reaction has been observed in-vivo in mice (Kumar et al., 2010). However, this cleavage happens at a site on fibrinogen without abolishing clotting completely. In addition, N.N venom is known to contain a prothrombin activator which promotes clot formation in-vitro. This clot is said to have an altered structure with low in elasticity (Sundell et al., 2003). The venom also has a weak plasmin-like activity (Gowtham et al., 2012) which could delay the clot formation by increasing fibrinolysis. Low concentrations of ASV $(5 \mu \mathrm{l})$ supplemented with MAP $(100 \mu \mathrm{g})$ was not only highly effective in normalizing PT in both Group 1 and Group 2 experiments, but also had a potentiating effect. Such observations have been made previously by Gomes et al. with Naja kaouthia venom and the methanolic extract of Pluchea indica (Gomes et al., 2007) and also by Chatterjee et al. with $N$. kaouthia and Hemidesmus indicus (Chatterjee, Chakravarty and Gomes, 2006). This gives credence to a combination therapy of using an herbal extract in addition to ASV in N.N bite.

The TT measures the time taken for the conversion of fibrinogen to fibrin by thrombin, a serine protease in the common pathway of clotting. ASV was effective in normalizing TT in Group 1 experiments, which proves that enzymes such as NN-PF3 in N.N venom (Kumar et al., 2010) which degrade fibrinogen and thereby prolong the TT, are neutralized by ASV. However, when the venom was given sufficient time to degrade the fibrinogen in plasma as in Group 2 experiments, the effect of ASV was very limited due to the irreversible nature of the digestion by fibrinogenolytic enzymes.

The coagulation cascade is also known to be inhibited by various phytochemicals such as polyphenols, sulfated polysaccharides through inhibition or decreased activity 
Table 1 Effects of ASV, MAP and their combination on N.N venom induced changes in aPTT without prior incubation of the plasma with venom

\begin{tabular}{|c|c|c|}
\hline Serial No & Groups & aPTT in seconds $($ Mean \pm SEM $)$ \\
\hline 1 & Plasma control $(\mathrm{P})$ & $30.9 \pm 0.5$ \\
\hline 2 & $\begin{array}{l}\mathrm{P}+\mathrm{MAP}(30 \mu \mathrm{g}) \\
{[\mathrm{MAP} \text { control-1] }}\end{array}$ & $30 \pm 0.5$ \\
\hline 3 & $\begin{array}{l}\text { P + MAP }(60 \mu \mathrm{g}) \\
{[\text { MAP control-2] }}\end{array}$ & $32 \pm 0.1$ \\
\hline 4 & $\begin{array}{l}\text { P + MAP }(120 \mu \mathrm{g}) \\
{[\text { MAP control-3] }}\end{array}$ & $32.1 \pm 0.2$ \\
\hline 5 & $\begin{array}{l}\text { P + MAP }(150 \mu \mathrm{g}) \\
{[\text { MAP control-4] }}\end{array}$ & $35 \pm 0.5$ \\
\hline 6 & $\begin{array}{l}\mathrm{P}+\mathrm{N} . \mathrm{N} \text { venom }(3 \mu \mathrm{g}) \\
{[\text { Venom control] }}\end{array}$ & $85 \pm 3.0 *(P=0.001)$ \\
\hline 7 & $\mathrm{P}+\mathrm{N} . \mathrm{N}$ venom $(3 \mu \mathrm{g})+\mathrm{ASV}(5 \mu \mathrm{l})$ & $46 \pm 0 * *(p=0.001)$ \\
\hline 8 & $\mathrm{P}+\mathrm{N} . \mathrm{N}$ venom $(3 \mu \mathrm{g})+\mathrm{ASV}(8 \mu \mathrm{l})$ & $43.5 \pm 0.5 * *(p=0.001)$ \\
\hline 9 & $\mathrm{P}+\mathrm{N} . \mathrm{N}$ venom $(3 \mu \mathrm{g})+\mathrm{ASV}(10 \mu \mathrm{l})$ & $40.1 \pm 0.1 * *(p=0.001)$ \\
\hline 10 & $\mathrm{P}+\mathrm{N} . \mathrm{N}$ venom $(3 \mu \mathrm{g})+\mathrm{ASV}(15 \mu \mathrm{l})$ & $27 \pm 2.0 * *(p=0.001)$ \\
\hline 11 & $\mathrm{P}+\mathrm{N} . \mathrm{N}$ venom $(3 \mu \mathrm{g})+\mathrm{MAP}(30 \mu \mathrm{g})$ & $77 \pm 7.0$ \\
\hline 12 & $\mathrm{P}+\mathrm{N} . \mathrm{N}$ venom $(3 \mu \mathrm{g})+\mathrm{MAP}(60 \mu \mathrm{g})$ & $69 \pm 4.0$ \\
\hline 13 & $\mathrm{P}+\mathrm{N} . \mathrm{N}$ venom $(3 \mu \mathrm{g})+\mathrm{MAP}(120 \mu \mathrm{g})$ & $54 \pm 2.0 * *(P=0.008)$ \\
\hline 14 & $\mathrm{P}+\mathrm{N} . \mathrm{N}$ venom $(3 \mu \mathrm{g})+\mathrm{MAP}(150 \mu \mathrm{g})$ & $46 \pm 4.0 * *(p=0.001)$ \\
\hline 15 & $\mathrm{P}+\mathrm{N} . \mathrm{N}$ venom $(3 \mu \mathrm{g})+\mathrm{MAP}(180 \mu \mathrm{g})$ & $46.5 \pm 0.5 * *(p=0.001)$ \\
\hline 16 & $\mathrm{P}+\mathrm{N} . \mathrm{N}$ venom $(3 \mu \mathrm{g})+\mathrm{ASV}(5 \mu \mathrm{l})+\mathrm{MAP}(30 \mu \mathrm{g})$ & $46.5 \pm 0.5 * *(p=0.001)$ \\
\hline 17 & $\mathrm{P}+\mathrm{N} . \mathrm{N}$ venom $(3 \mu \mathrm{g})+\mathrm{ASV}(5 \mu \mathrm{l})+\mathrm{MAP}(60 \mu \mathrm{g})$ & $42.5 \pm 0.5 * *(p=0.002)$ \\
\hline 18 & $\mathrm{P}+\mathrm{N} . \mathrm{N}$ venom $(3 \mu \mathrm{g})+\mathrm{ASV}(5 \mu \mathrm{l})+\mathrm{MAP}(120 \mu \mathrm{g})$ & $29 \pm 2.0 * * \$(P=0.007)$ \\
\hline 19 & $\mathrm{P}+\mathrm{N} . \mathrm{N}$ venom $(3 \mu \mathrm{g})+\mathrm{ASV}(5 \mu \mathrm{l})+\mathrm{MAP}(150 \mu \mathrm{g})$ & $35.5 \pm 0.5 * *(p=0.001)$ \\
\hline 20 & $\mathrm{P}+\mathrm{N} . \mathrm{N}$ venom $(3 \mu \mathrm{g})+\mathrm{ASV}(5 \mu \mathrm{l})+\mathrm{MAP}(180 \mu \mathrm{g})$ & $43 \pm 1.0 * *(p=0.001)$ \\
\hline
\end{tabular}

All values represent mean \pm SEM of triplicate samples where, $* p<0.05$ compared to plasma control, $* * p<0.05$ compared to $\mathrm{P}+\mathrm{N} . \mathrm{N}$ venom $(3 \mu \mathrm{g})$ [Venom control], ${ }^{\$} p<0.05$ compared to $\mathrm{P}+\mathrm{N} . \mathrm{N}$ venom $(10 \mu \mathrm{g})+\mathrm{ASV}(5 \mu \mathrm{l}) ; 5 \mu \mathrm{l}$ ASV contain $11 \mu \mathrm{g}$ Lowry protein

$A S V$ polyvalent anti-snake venom, MAP methanolic extract of Andrographis paniculata, N.N Naja naja, $a P T T$ activated partial thromboplastin time, $P$ plasma of thrombin, as well as potentiation of heparin co-factor II (Cordier and Steenkamp, 2012). Ineffectiveness of MAP in reversing TT seems to be due to loss of fibrinogen caused by N.N venom enzymes.

\section{Conclusion}

This study was an evaluation of the ability of ASV, MAP and their combination to normalize the hemostatic abnormalities induced by $\mathrm{NN}$ venom. The Indian polyvalent ASV was found to be effective in reversing the deleterious effects of the venom on the intrinsic, extrinsic and common pathways of clotting when the addition of venom was immediately followed by the addition of ASV. When the venom was incubated with plasma prior to the experiments, ASV was partially effective in reversing aPTT and TT, and could completely normalize PT. MAP when used alone, partially improved the aPTT and completely normalized PT. When used along with ASV, the effect of MAP on PT was interesting, in that, it had a potentiating effect on the action of ASV in normalizing it. However, MAP had a deleterious effect on TT, prolonging it beyond control values. However, the beneficial effects of supplementing ASV with MAP have to be assessed comprehensively. In addition to causing hemostatic abnormalities, by virtue of the presence of 81 different toxins, the NN venom affects all organ systems. It has already been conclusively proven that a combination of ASV and MAP are effective in preventing toxic systemic effects such as spreading of the venom by inhibiting hyaluronidase and neurotoxicity by inhibition of venom acetylcholinesterase (Nayak, Kumar, et al., 2020). This study thus conclusively evaluated and proved that the beneficial effects of the combination of ASV with MAP, were multifaceted. The merits extend not only to the mitigation of hemostatic abnormalities but also to a drastic reduction of the use of ASV by $70 \%$. In the Indian context, where the number of snake bites are as many as 50,000 per year, such a strategy implies a better outcome with limited resources, thus reducing the economic burden on snakebite victims. 
Fig. 6 Effect of ASV, MAP and ASV + MAP on N.N venominduced changes in TT with prior incubation of normal citrated plasma with venom at $37^{\circ} \mathrm{C}$ for $90 \mathrm{~min}$. $A S V$ anti-snake venom; $M A P$ methanolic extract of Andrographis paniculata; N.N Naja naja; TT thrombin time
$0.2 \mathrm{ml}$ citrated plasma (pre-warmed at $37^{\circ} \mathrm{C}$ )

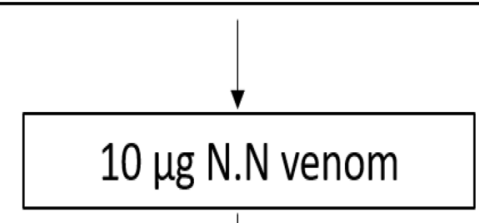

Mixed well \& incubated at $37^{\circ} \mathrm{C}$ for 90 minutes

$\operatorname{ASV}(5 \mu l, 10 \mu l$ and $17 \mu l)$

or

$\operatorname{MAP}(10 \mu \mathrm{g}, 100 \mu \mathrm{g}$ and $200 \mu \mathrm{g})$

or

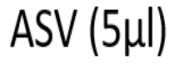

$+$

$\operatorname{MAP}(10 \mu \mathrm{g}, 100 \mu \mathrm{g}$ and $200 \mu \mathrm{g})$

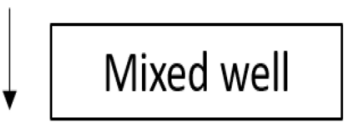

Add $0.1 \mathrm{ml}$ Thrombin reagent

(kept at room temperature)

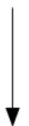

Record the clotting time using a stop watch 
Table 2 Effects of ASV, MAP and their combination on N.N venom induced changes in PT and TT without prior incubation of the plasma with venom

\begin{tabular}{|c|c|c|c|}
\hline Serial No & Group & $\mathrm{PT}$ in seconds $($ Mean $\pm \mathrm{SEM})$ & TT in seconds (Mean \pm SEM) \\
\hline 1 & Plasma control $(\mathrm{P})$ & $12.2 \pm 0.41$ & $14.06 \pm 0.06$ \\
\hline 2 & $\mathrm{P}+\mathrm{MAP}(10 \mu \mathrm{g})[\mathrm{MAP}$ control-1] & $13.1 \pm 0.3$ & $32 \pm 0.5$ \\
\hline 3 & P + MAP $(100 \mu \mathrm{g})[$ MAP control-2] & $14 \pm 0.2$ & $36 \pm 0.1$ \\
\hline 4 & P + MAP $(200 \mu \mathrm{g})[$ MAP control-3] & $12.5 \pm 0.12$ & $38 \pm 0.2$ \\
\hline 5 & $\mathrm{P}+\mathrm{N} . \mathrm{N}$ venom $(10 \mu \mathrm{g})[$ Venom control] & $18.16 \pm 0.44 *(p=0.001)$ & $18.86 \pm 0.27 *(p=0.001)$ \\
\hline 6 & $\mathrm{P}+\mathrm{N} . \mathrm{N}$ venom $(10 \mu \mathrm{g})+\mathrm{ASV}(5 \mu \mathrm{l})$ & $16.8 \pm 0.16$ & $17.3 \pm 0.42$ \\
\hline 7 & $\mathrm{P}+\mathrm{N} . \mathrm{N}$ venom $(10 \mu \mathrm{g})+\mathrm{ASV}(10 \mu \mathrm{l})$ & $14.5 \pm 0.28 * *(p=0.001)$ & $16.2 \pm 0.2 * *(p=0.02)$ \\
\hline 8 & $\mathrm{P}+\mathrm{N} . \mathrm{N}$ venom $(10 \mu \mathrm{g})+\mathrm{ASV}(17 \mu \mathrm{l})$ & $12.16 \pm 0.72 * *(p=0.001)$ & $13.63 \pm 0.18 * *(p=0.001)$ \\
\hline 9 & $\mathrm{P}+\mathrm{N} . \mathrm{N}$ venom $(10 \mu \mathrm{g})+\mathrm{MAP}(10 \mu \mathrm{g})$ & $16.5 \pm 0.28$ & $41.33 \pm 0.88 * *(0.001)$ \\
\hline 10 & $\mathrm{P}+\mathrm{N} . \mathrm{N}$ venom $(10 \mu \mathrm{g})+\mathrm{MAP}(100 \mu \mathrm{g})$ & $13.26 \pm 0.37 * *(p=0.001)$ & $22.83 \pm 0.6^{* *}(p=0.001)$ \\
\hline 11 & $\mathrm{P}+\mathrm{N} . \mathrm{N}$ venom $(10 \mu \mathrm{g})+\mathrm{MAP}(200 \mu \mathrm{g})$ & $17.67 \pm 0.16$ & $23.13 \pm 0.59 * *(p=0.001)$ \\
\hline 12 & $\mathrm{P}+\mathrm{N} . \mathrm{N}$ venom $(10 \mu \mathrm{g})+\mathrm{ASV}(5 \mu \mathrm{l})+\mathrm{MAP}(10 \mu \mathrm{g})$ & $13.9 \pm 0.14 * * \$(p=0.001)$ & $38.63 \pm 0.4 * * \$(p=0.001)$ \\
\hline 13 & $\mathrm{P}+\mathrm{N} . \mathrm{N}$ venom $(10 \mu \mathrm{g})+\mathrm{ASV}(5 \mu \mathrm{l})+\mathrm{MAP}(100 \mu \mathrm{g})$ & $12.5 \pm 0.29 * * \$(p=0.001)$ & $27.13 \pm 0.5 * * \$(p=0.001)$ \\
\hline 14 & $\mathrm{P}+\mathrm{N} . \mathrm{N}$ venom $(10 \mu \mathrm{g})+\mathrm{ASV}(5 \mu \mathrm{l})+\mathrm{MAP}(200 \mu \mathrm{g})$ & $17.13 \pm 0.13$ & $27.7 \pm 0.6 * * \$(p=0.001)$ \\
\hline
\end{tabular}

All values represent mean \pm SEM of triplicate samples where, ${ }^{*} p<0.05$ compared to plasma control (49\% increase in PT, $34 \%$ increase in TT), ${ }^{* * *} p<0.05$ compared to P+N.N venom $(10 \mu \mathrm{g})$ [Venom control], ${ }^{\$} p<0.05$ compared to P+N.N venom $(10 \mu \mathrm{g})+\mathrm{ASV}(5 \mu \mathrm{l}) ; 5 \mu \mathrm{l}$ ASV contain $11 \mu \mathrm{g}$ Lowry protein

$A S V$ polyvalent anti-snake venom, MAP methanolic extract of Andrographis paniculata, N.N Naja naja, PT prothrombin time, TT thrombin time, $P$ plasma

Fig. 7 Comparison of effects of combination of ASV and MAP with ASV alone in reducing the N.N venom-induced increase in aPTT without prior incubation of plasma with venom at $37^{\circ} \mathrm{C}$ for $90 \mathrm{~min}$. Legends: All values represents mean \pm SEM of three values, where $* p<0.05$ compared to plasma control $(\mathrm{P}) ;{ }^{* *} p<0.05$ compared to $\mathrm{P}+\mathrm{N} . \mathrm{N}$ venom $(3 \mu \mathrm{g}) ;{ }^{\$} p<0.05$ compared to $\mathrm{P}+\mathrm{N}$.N venom $(3 \mu \mathrm{g})+\mathrm{ASV}(5 \mu \mathrm{l}) . A S V$ polyvalent anti-snake venom; $M A P$ methanolic extract of Andrographis paniculata; N.N Naja naja; aPTT activated partial thromboplastin time; $\mathrm{P}$ plasma

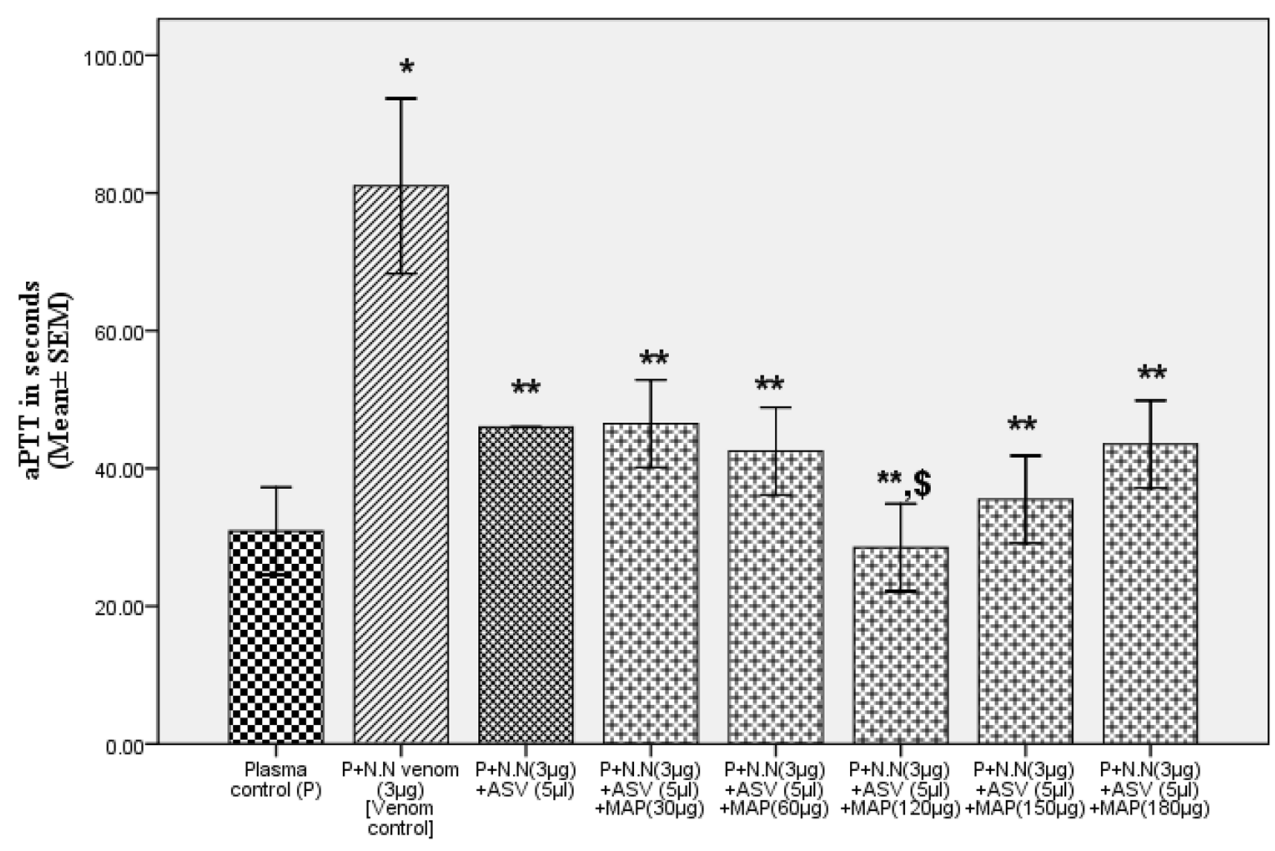


Table 3 Effects of ASV, MAP and their combination on N.N venom induced changes in aPTT with prior incubation of the plasma with venom at $37^{\circ} \mathrm{C}$ for $90 \mathrm{~min}$

\begin{tabular}{|c|c|c|}
\hline Serial No & Group & $\begin{array}{l}\text { APTT in seconds } \\
(\text { Mean } \pm \text { SEM })\end{array}$ \\
\hline 1 & Plasma control $(\mathrm{P})$ & $30.9 \pm 0.5$ \\
\hline 2 & $\mathrm{P}+\mathrm{N} . \mathrm{N}$ venom $(3 \mu \mathrm{g})[$ Venom control] & $102.5 \pm 5.5 *(p=0.001)$ \\
\hline 3 & $\mathrm{P}+\mathrm{N} . \mathrm{N}$ venom $(3 \mu \mathrm{g})+\mathrm{ASV}(5 \mu \mathrm{l})$ & $70 \pm 2.0 * *(p=0.001)$ \\
\hline 4 & $\mathrm{P}+\mathrm{N} . \mathrm{N}$ venom $(3 \mu \mathrm{g})+\mathrm{ASV}(8 \mu \mathrm{l})$ & $48.5 \pm 1.5 * *(p=0.001)$ \\
\hline 5 & $\mathrm{P}+\mathrm{N} . \mathrm{N}$ venom $(3 \mu \mathrm{g})+\mathrm{ASV}(10 \mu \mathrm{l})$ & $59 \pm 1.0 * *(p=0.001)$ \\
\hline 6 & $\mathrm{P}+\mathrm{N} . \mathrm{N}$ venom $(3 \mu \mathrm{g})+\mathrm{ASV}(15 \mu \mathrm{l})$ & $71 \pm 1.0 * *(p=0.001)$ \\
\hline 7 & $\mathrm{P}+\mathrm{N} . \mathrm{N}$ venom $(3 \mu \mathrm{g})+\mathrm{MAP}(30 \mu \mathrm{g})$ & $78 \pm 8.0 * *(p=0.05)$ \\
\hline 8 & $\mathrm{P}+\mathrm{N} . \mathrm{N}$ venom $(3 \mu \mathrm{g})+\mathrm{MAP}(60 \mu \mathrm{g})$ & $56.5 \pm 2.05 * *(p=0.003)$ \\
\hline 9 & $\mathrm{P}+\mathrm{N} . \mathrm{N}$ venom $(3 \mu \mathrm{g})+\mathrm{MAP}(120 \mu \mathrm{g})$ & $75 \pm 5.0 * *(p=0.03)$ \\
\hline 10 & $\mathrm{P}+\mathrm{N} . \mathrm{N}$ venom $(3 \mu \mathrm{g})+\mathrm{MAP}(150 \mu \mathrm{g})$ & $85 \pm 5.0$ \\
\hline 11 & $\mathrm{P}+\mathrm{N} . \mathrm{N}$ venom $(3 \mu \mathrm{g})+\mathrm{MAP}(180 \mu \mathrm{g})$ & $96 \pm 4.0$ \\
\hline 12 & $\mathrm{P}+\mathrm{N} . \mathrm{N}$ venom $(3 \mu \mathrm{g})+\mathrm{ASV}(5 \mu \mathrm{l})+\mathrm{MAP}(30 \mu \mathrm{g})$ & $67.5 \pm 2.5 * *(p=0.001)$ \\
\hline 13 & $\mathrm{P}+\mathrm{N} \cdot \mathrm{N}$ venom $(3 \mu \mathrm{g})+\mathrm{ASV}(5 \mu \mathrm{l})+\mathrm{MAP}(60 \mu \mathrm{g})$ & $50 \pm 4.0 * *, \$(p=0.001)$ \\
\hline 14 & $\mathrm{P}+\mathrm{N} . \mathrm{N}$ venom $(3 \mu \mathrm{g})+\mathrm{ASV}(5 \mu \mathrm{l})+\mathrm{MAP}(120 \mu \mathrm{g})$ & $77.5 \pm 2.5 * *(p=0.007)$ \\
\hline 15 & $\mathrm{P}+\mathrm{N} . \mathrm{N}$ venom $(3 \mu \mathrm{g})+\mathrm{ASV}(5 \mu \mathrm{l})+\mathrm{MAP}(150 \mu \mathrm{g})$ & $82 \pm 2.0 * *(p=0.018)$ \\
\hline 16 & $\mathrm{P}+\mathrm{N} . \mathrm{N}$ venom $(3 \mu \mathrm{g})+\mathrm{ASV}(5 \mu \mathrm{l})+\mathrm{MAP}(180 \mu \mathrm{g})$ & $87.5 \pm 2.5$ \\
\hline
\end{tabular}

All values represent mean \pm SEM of triplicate samples where $* p<0.05$ compared to plasma control (231\% increase), ${ }^{* *} p<0.05$ compared to P+N.N venom ( $3 \mu \mathrm{g}$ ) [Venom Control]; ${ }^{\$} p<0.05$ compared to P+N.N venom $(10 \mu \mathrm{g})+\operatorname{ASV}(5 \mu \mathrm{l}), 5 \mu \mathrm{l}$ ASV contain $11 \mu \mathrm{g}$ Lowry protein

$A S V$ polyvalent anti-snake venom, MAP methanolic extract of Andrographis paniculata, N.N Naja naja, $a P T T$ activated partial thromboplastin time, $P$ plasma

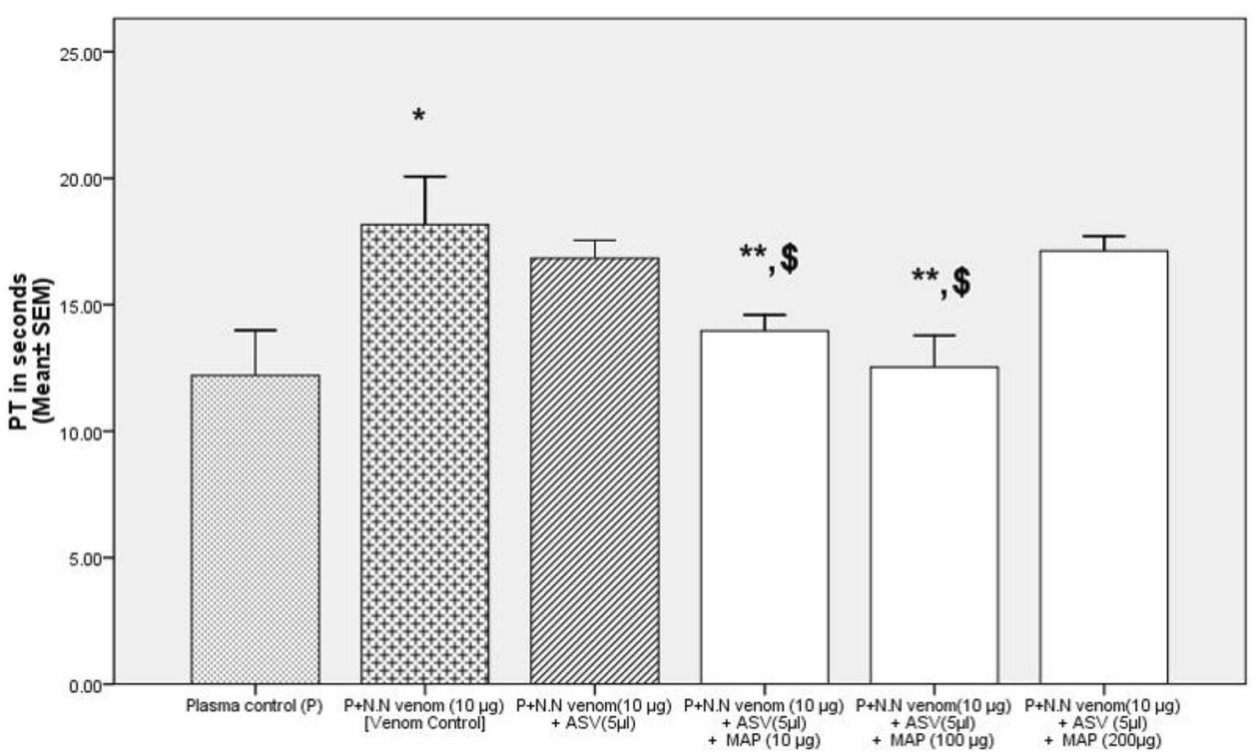

Fig. 8 Comparison of effects of combination of polyvalent ASV and MAP with ASV alone on N.N venom-induced increase in PT without prior incubation of plasma with N.N venom. Legends: All values represents mean \pm SEM of three values, where $* p<0.05$ compared to plasma control; ${ }^{* *} p<0.05$ compared to $\mathrm{P}+\mathrm{N} . \mathrm{N}$ venom $(10 \mu \mathrm{g})$ [Venom control]; ${ }^{\$} p<0.05$ compared to $\mathrm{P}+\mathrm{N} . \mathrm{N}$ venom $(10 \mu \mathrm{g})+\mathrm{ASV}(5 \mu \mathrm{l}) . A S V$ polyvalent anti-snake venom, $M A P$ methanolic extract of Andrographis paniculata, N.N Naja naja, $P T$ prothrombin time; $P$ plasma 
Table 4 Effects of ASV, MAP and their combination on N.N venom induced changes in PT and TT with prior incubation of the plasma with venom at $37^{\circ} \mathrm{C}$ for $90 \mathrm{~min}$

\begin{tabular}{|c|c|c|c|}
\hline Serial No & Group & $\mathrm{PT}$ in seconds (Mean $\pm \mathrm{SEM})$ & TT in seconds $($ Mean $\pm \mathrm{SEM})$ \\
\hline 1 & Plasma control $(\mathrm{P})$ & $12.2 \pm 0.41$ & $14.06 \pm 0.06$ \\
\hline 2 & $\mathrm{P}+\mathrm{N} . \mathrm{N}$ venom $(10 \mu \mathrm{g})($ Venom control $)$ & $50.3 \pm 1.2 *(p=0.001)$ & $48.46 \pm 1.57 *(p=0.001)$ \\
\hline 3 & $\mathrm{P}+\mathrm{N} . \mathrm{N}$ venom $(10 \mu \mathrm{g})+\mathrm{ASV}(5 \mu \mathrm{l})$ & $28.13 \pm 0.59 * *(p=0.001)$ & $42.8 \pm 0.6 * *(p=0.002)$ \\
\hline 4 & $\mathrm{P}+\mathrm{N} . \mathrm{N}$ venom $(10 \mu \mathrm{g})+\mathrm{ASV}(10 \mu \mathrm{l})$ & $22.66 \pm 0.88 * *(p=0.001)$ & $38.3 \pm 0.37 * *(p=0.001)$ \\
\hline 5 & $\mathrm{P}+\mathrm{N} . \mathrm{N}$ venom $(10 \mu \mathrm{g})+\mathrm{ASV}(17 \mu \mathrm{l})$ & $14.16 \pm 0.60 * *(p=0.001)$ & $33.6 \pm 0.24 * *(p=0.001)$ \\
\hline 6 & $\mathrm{P}+\mathrm{N} . \mathrm{N}$ venom $(10 \mu \mathrm{g})+\mathrm{MAP}(10 \mu \mathrm{g})$ & $41.66 \pm 0.88 * *(p=0.001)$ & $57.2 \pm 0.5 * *(p=0.001)$ \\
\hline 7 & $\mathrm{P}+\mathrm{N} . \mathrm{N}$ venom $(10 \mu \mathrm{g})+\mathrm{MAP}(100 \mu \mathrm{g})$ & $50.0 \pm 1.15$ & $62.8 \pm 0.9 * *(\mathrm{p}=0.001)$ \\
\hline 8 & $\mathrm{P}+\mathrm{N} . \mathrm{N}$ venom $(10 \mu \mathrm{g})+\mathrm{MAP}(200 \mu \mathrm{g})$ & $54.46 \pm 2.26$ & $61.7 \pm 0.6 * *(p=0.001)$ \\
\hline 9 & $\mathrm{P}+\mathrm{N} . \mathrm{N}$ venom $(10 \mu \mathrm{g})+\mathrm{ASV}(5 \mu \mathrm{l})+\mathrm{MAP}(10 \mu \mathrm{g})$ & $29.66 \pm 1.45 * *(p=0.001)$ & $48.4 \pm 0.8$ \\
\hline 10 & $\mathrm{P}+\mathrm{N} . \mathrm{N}$ venom $(10 \mu \mathrm{g})+\mathrm{ASV}(5 \mu \mathrm{l})+\mathrm{MAP}(100 \mu \mathrm{g})$ & $20.33 \pm 1.45 * *, \$(p=0.001)$ & $52.2 \pm 1.02$ \\
\hline 11 & $\mathrm{P}+\mathrm{N} . \mathrm{N}$ venom $(10 \mu \mathrm{g})+\mathrm{ASV}(5 \mu \mathrm{l})+\mathrm{MAP}(200 \mu \mathrm{g})$ & $37.46 \pm 1.36 * *, \$(p=0.001)$ & $60.06 \pm 1.2 * *, \$(p=0.001)$ \\
\hline
\end{tabular}

All values represent mean \pm SEM of triplicate samples where $* p<0.05$ compared to plasma control ( $312 \%$ increase in PT, $245 \%$ increase in TT); ${ }^{* *} p<0.05$ compared to P+N.N venom $(10 \mu \mathrm{g})$ [Venom control]; ${ }^{\$} p<0.05$ compared to P+N.N venom $(10 \mu \mathrm{g})+\mathrm{ASV}(5 \mu \mathrm{l}) ; 5 \mu \mathrm{l}$ ASV contain $11 \mu \mathrm{g}$ Lowry protein

ASV polyvalent anti-snake venom, MAP methanolic extract of Andrographis paniculata, N.N Naja naja, PT prothrombin time, TT thrombin time, $P$ plasma

Fig. 9 Comparison of effects of combination of ASV and MAP with ASV alone in reducing the N.N venom-induced increase in aPTT with prior incubation of plasma with venom at $37^{\circ} \mathrm{C}$ for $90 \mathrm{~min}$. All values represents mean \pm SEM of three values, where $* p<0.05$ compared to plasma control (231\% increase); $* * p<0.05$ compared to P+N.N venom $(3 \mu \mathrm{g}) ;{ }^{\$} p<0.05$ compared to $\mathrm{P}+\mathrm{N} . \mathrm{N}$ venom $(3 \mu \mathrm{g})+\mathrm{ASV}(5 \mu \mathrm{l}) . A S V$ polyvalent anti-snake venom, $M A P$ methanolic extract of Andrographis paniculata, N.N Naja naja, aPTT activated partial thromboplastin time, $P$ plasma

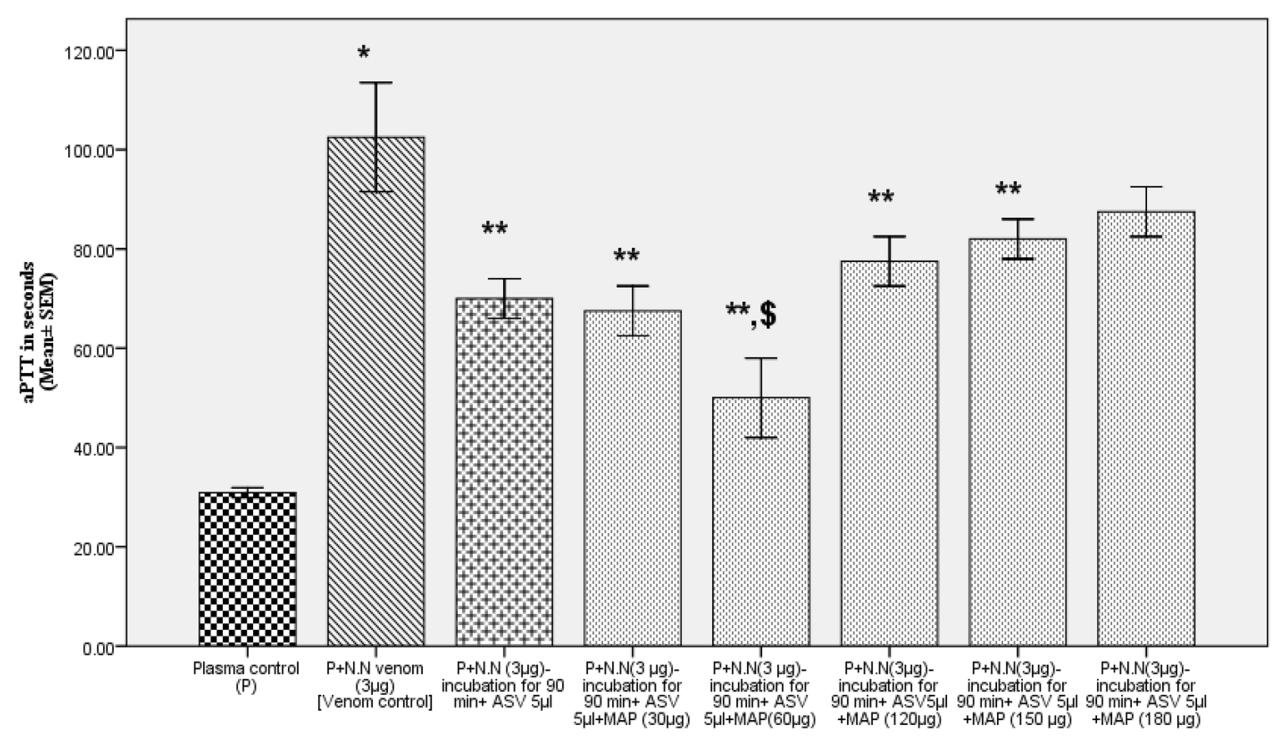


Fig.10 Comparison of effects of combination of polyvalent ASV and MAP with ASV alone on N.N venom-induced increase in PT, with prior incubation of plasma with N.N venom at $37^{\circ} \mathrm{C}$ for $90 \mathrm{~min}$. All values represents mean \pm SEM of three values, where $* p<0.05$ compared to plasma control; ${ }^{* *} p<0.05$ compared to $\mathrm{P}+\mathrm{N} . \mathrm{N}$ venom $(10 \mu \mathrm{g})$ [Venom control]; ${ }_{p}<<0.05$ compared to $\mathrm{P}+\mathrm{N} . \mathrm{N}$ venom $(10 \mu \mathrm{g})$ - after $90 \mathrm{~min}$ ASV $(5 \mu \mathrm{l}) . A S V$ polyvalent anti-snake venom, MAP methanolic extract of Andrographis paniculata, N.N Naja naja, PT prothrombin time

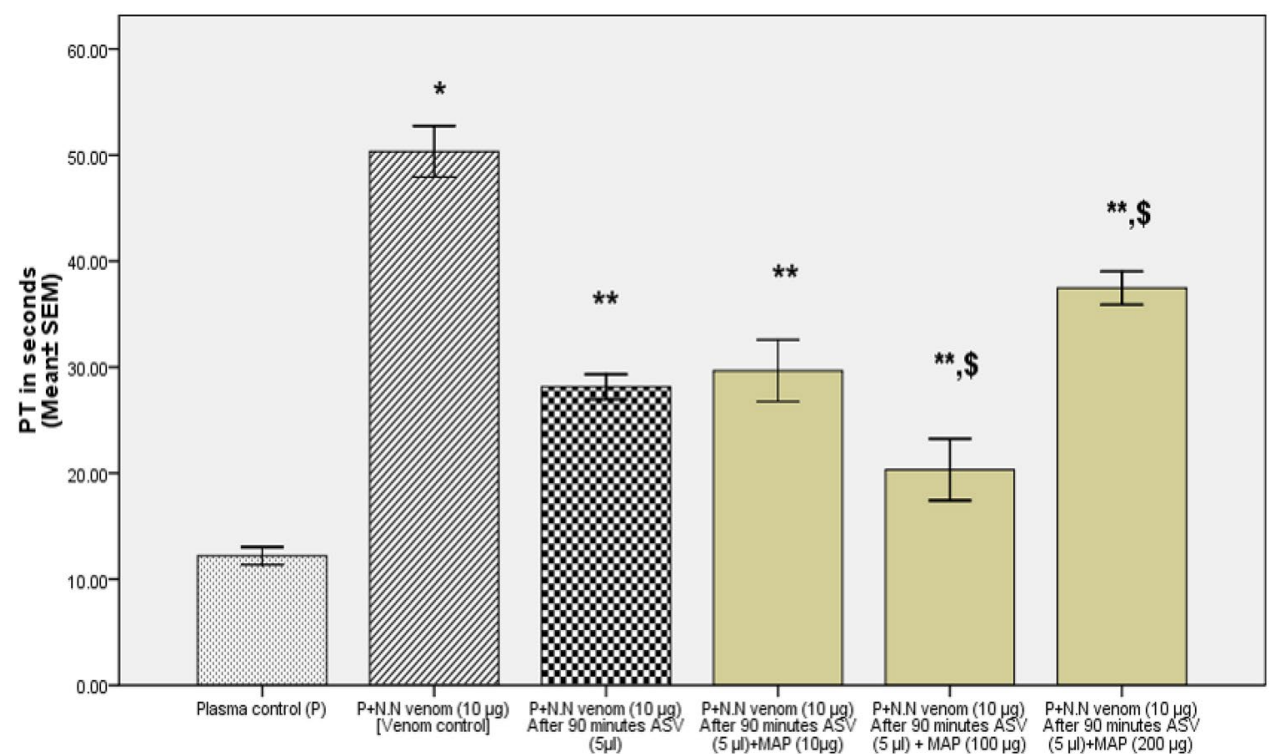

Acknowledgement We would like to thank the Department of Clinical Pathology and Hematology Laboratory of Kasturba Medical Hospital, Manipal, Department of Biochemistry, Kasturba Medical College, Manipal and Melaka Manipal Medical College (Manipal Campus), Manipal Academy of Higher Education, Manipal, India, for providing infrastructural support to carry out this research work. We would also like to thank Natural Remedies Pvt Ltd, Bangalore for providing a sample of methanolic extract of Andrographis paniculata for the study.

Funding Open access funding provided by Manipal Academy of Higher Education, Manipal.

Open Access This article is licensed under a Creative Commons Attribution 4.0 International License, which permits use, sharing, adaptation, distribution and reproduction in any medium or format, as long as you give appropriate credit to the original author(s) and the source, provide a link to the Creative Commons licence, and indicate if changes were made. The images or other third party material in this article are included in the article's Creative Commons licence, unless indicated otherwise in a credit line to the material. If material is not included in the article's Creative Commons licence and your intended use is not permitted by statutory regulation or exceeds the permitted use, you will need to obtain permission directly from the copyright holder. To view a copy of this licence, visit http://creativecommons.org/licenses/by/4.0/.

\section{References}

Adcock DM, Hoefner DM, Kottke-Marchant K, Marlar RA (2008) Collection, transport, and processing of blood specimens for testing plasma-based coagulation assays and molecular hemostasis assays. CLSI Approved Guideline-Fifth Edition. H21-A5, Nccls, 28(5), pp H21-A5. Available at: www.clsi.org.

Ahmed S et al (2008) Emergency treatment of a snake bite: pearls from literature. J Emerg Trauma Shock 1(2):97-105. https://doi.org/10. 4103/0974-2700.43190

Alam MI (2014) Inhibition of toxic effects of viper and cobra venom by indian medicinal plants. Pharmacol Pharm. https://doi.org/10. 4236/pp.2014.58093
Bain IB, BJ MAL (2017) Dacie and Lewis practical haematology. Elsevier, Dacie and Lewis practical haematology. https://doi.org/10. 1016/c2014-0-01046-5

Barber CM, Isbister GK, Hodgson WC (2013) Alpha neurotoxins. Toxicon. 66:47. https://doi.org/10.1016/j.toxicon.2013.01.019

Berling I, Isbister GK (2015) Hematologic effects and complications of snake envenoming. Transfus Med Rev 29(2):82-89. https://doi. org/10.1016/J.TMRV.2014.09.005

Chatterjee I, Chakravarty AK, Gomes A (2006) Daboia russellii and Naja kaouthia venom neutralization by lupeol acetate isolated from the root extract of Indian sarsaparilla Hemidesmus indicus R.Br. J Ethnopharmacol 106(1):38-43. https://doi.org/10.1016/j. jep.2005.11.031

Chayamiti T, Mwenje E, Mahamadi C (2013) African journal of pharmacy and pharmacology spectrophotometric study of the anticaseinolytic activity of root extracts of teclea nobilis and vepris zambesiaca on bitis arietans venom. Afr J Pharm Pharmacol 7(21):1420-1425. https://doi.org/10.5897/AJPP2013.3514

Chen Y et al (2020) Hemostatic action of lotus leaf charcoal is probably due to transformation of flavonol aglycons from flavonol glycosides in traditional Chinses medicine. J Ethnopharmacol. https:// doi.org/10.1016/j.jep.2019.112364

Choudhury $\mathrm{M}$ et al (2017) Comparison of proteomic profiles of the venoms of two of the 'Big Four' snakes of India, the Indian 2 cobra (Naja naja) and the common krait (Bungarus caeruleus), and analyses of their toxins. Toxicon. https://doi.org/10.1016/j. toxicon.2017.06.005

Chube SP et al (2016) A cross-sectional study to observe the effects of dose of anti-snake venom on outcomes and adverse effects in snake bite cases. Int J Med Sci Public Health Online 5(12):24662470. https://doi.org/10.5455/ijmsph.2016.04052016496

Cordier W, Steenkamp V (2012) Herbal remedies affecting coagulation: a review. Pharm Biol 50(4):443-452. https://doi.org/10. 3109/13880209.2011.611145

Deshpande RP et al (2013) Adverse drug reaction profile of antisnake venom in a rural tertiary care teaching hospital. J Young Pharm : JYP 5(2):41-5. https://doi.org/10.1016/j.jyp.2013.02. 003

Dhananjaya BL et al (2006) Anticoagulant effect of Naja naja venom 5'nucleotidase: demonstration through the use of novel specific inhibitor, vanillic acid. Toxicon 48(4):411-421. https://doi.org/ 10.1016/j.toxicon.2006.06.017 
Dissanayake DSB et al (2018) The venom of spectacled cobra (Elapidae: Naja naja): in vitro study from distinct geographical origins in Sri Lanka. J Toxicol. 2018:1-14. https://doi.org/10.1155/ 2018/7358472

Dutta S, Gogoi D, Mukherjee AK (2015) Anticoagulant mechanism and platelet deaggregation property of a non-cytotoxic, acidic phospholipase A2 purified from Indian cobra (Naja naja) venom: inhibition of anticoagulant activity by low molecular weight heparin. Biochimie 110:93-106. https://doi.org/10.1016/j.biochi.2014. 12.020

Girish KS, Kemparaju K (2005) Inhibition of Naja naja venom hyaluronidase by plant-derived bioactive components and polysaccharides. Biokhimiya 70(8):1145-1150

Gomes A et al (2007) Viper and cobra venom neutralization by $\beta$-sitosterol and stigmasterol isolated from the root extract of Pluchea indica Less. (Asteraceae). Phytomedicine 14(9):637-643. https://doi.org/10.1016/j.phymed.2006.12.020

Gopi, K. et al. (2011) 'The neutralization effect of methanol extract of Andrographis paniculata on Indian cobra Naja naja snake venom'. Conflict, 4(4), pp. 1010-1012. Available at: http://jprsolutions. info.

Gowda CDR et al (2006) Differential action of proteases from Trimeresurus malabaricus, Naja naja and Daboia russellii venoms on hemostasis. Comp Biochem Physiol C: Toxicol Pharmacol 143(3):295-302. https://doi.org/10.1016/J.CBPC.2006.03.001

Gowtham YJ et al (2012) Hemostatic interference of Indian king cobra (Ophiophagus hannah) venom. comparison with three other snake venoms of the subcontinent. Biochem Mosc 77(6):639-647. https://doi.org/10.1134/S0006297912060119

Kumar MS et al (2010) Anti-coagulant activity of a metalloprotease: further characterization from the Indian cobra (Naja naja) venom. J Thromb Thrombolysis 29(3):340-348. https://doi.org/10.1007/ s11239-009-0379-2

Kumar MS et al (2011) The metalloprotease, NN-PF3 from Naja naja venom inhibits platelet aggregation primarily by affecting $\alpha 2 \beta 1$ integrin. Ann Hematol 90(5):569-577. https://doi.org/10.1007/ s00277-010-1103-1

Liang W et al (2019) Genus Liparis: A review of its traditional uses in China, phytochemistry and pharmacology. J Ethnopharmacol 234:154-171. https://doi.org/10.1016/j.jep.2019.01.021

Mani, M. A. (2015) Andrographis paniculata leaf extracts as potential Naja naja anti-snake venom. Available at: https://www.resea rchgate.net/publication/287996271_ANDROGRAPHIS_PANIC ULATA_LEAF_EXTRACTS_AS_POTENTIAL_NAJA_NAJA_ ANTI-SNAKE_VENOM (Accessed: 8 February 2021).

Nayak AG, Kumar N et al (2020) Anti-snake venom and methanolic extract of Andrographis paniculata: a multipronged strategy to neutralize Naja naja venom acetylcholinesterase and hyaluronidase. 3 Biotech 10(11):1-12. https://doi.org/10.1007/ s13205-020-02462-4

Nayak AG, Ahammad J et al (2020) Can the methanolic extract of Andrographis paniculata be used as a supplement to anti-snake venom to normalize hemostatic parameters: a thromboelastographic study. J Ethnopharmacol 252:112480. https://doi.org/10. 1016/j.jep.2019.112480

Paoli M et al (2009) Mass spectrometry analysis of the phospholipase A2 activity of snake pre-synaptic neurotoxins in cultured neurons. J Neurochem 111(3):737-744. https://doi.org/10.1111/j. 1471-4159.2009.06365.x
Premendran SJ et al (2011) Anti-cobra venom activity of plant Andrographis paniculata and its comparison with polyvalent anti-snake venom. J Nat Sci Biol Med 2(2):198-204. https://doi.org/10.4103/ 0976-9668.92326

Kumar RS, Joshua AV, Sangeetha M, Thilagavathy D, Gnanaiah S (2014) Isolation, purification and characterization of active compound from Andrographis paniculata 1 and phyllanthus amarus 1 and testing the antivenom activity of the di-herbal extract by invitro and invivo studies. Int Res J Pharm. 5(3):207-211. https:// doi.org/10.7897/2230-8407.050344

Rajesh KS et al (2017) Neutralization of Naja naja venom induced lethality, edema and myonecrosis by ethanolic root extract of Coix lacryma-jobi. Toxicol Rep 4:637-645. https://doi.org/10.1016/j. toxrep.2017.11.005

Ranawaka UK, Lalloo DG, de Silva HJ (2013) Neurotoxicity in snakebite-the limits of our knowledge. PLoS Negl Trop Dis 7(10):e2302. https://doi.org/10.1371/journal.pntd.0002302

Randall RJ, Lewis A (1951) Protein measurement with the folin phenol reagent. J Biol Chem 193:265-275

Rucavado A, Escalante T, Gutiérrez JM (2004) Effect of the metalloproteinase inhibitor batimastat in the systemic toxicity induced by Bothrops asper snake venom: understanding the role of metalloproteinases in envenomation. Toxicon 43:417-424. https://doi. org/10.1016/j.toxicon.2004.01.016

Satish S, Tejaswini J, Krishnakantha TP, Veerabasappa Gowda T (2004) Purification of a Class B1 platelet aggregation inhibitor phospholipase A2 from Indian cobra (Naja Naja) venom. Biochimie 86(3):203-210

Sareer O, Ahad A, Umar S (2012) Prophylactic and lenitive effects of Andrographis paniculata against common human ailments: an exhaustive and comprehensive reappraisal. J Pharm Res. Available at: https://scinapse.io/papers/605789991. Accessed 27 Dec 2019

Shafqat J, Zaidi ZH, Jörnvall H (1990) Purification and characterization of a chymotrypsin Kunitz inhibitor type of polypeptide fro the venom of cobra (Naja naja naja). FEBS Lett 275(1-2):6-8. https://doi.org/10.1016/0014-5793(90)81426-O

De Silva HA, Ryan NM, De Silva HJ (2016) Adverse reactions to snake antivenom, and their prevention and treatment. Br J Clin Pharmacol 81(3):446-452. https://doi.org/10.1111/bcp.12739

Sivakumar A, Manikandan A, R. R. M. and J. G. (2015) Andrographis paniculata leaf extracts as potential Naja Naja anti-snake venom. World J Pharm Pharm Sci 4(12):1036-1050

Sundell IB et al (2003) In vitro procoagulant and anticoagulant properties of Naja naja naja venom. Toxicon 42(3):239-247. https://doi. org/10.1016/S0041-0101(03)00137-5

Suvilesh KN et al (2017) Purification and characterization of an antihemorrhagic protein from Naja naja (Indian cobra) venom. Toxicon 140:83-93. https://doi.org/10.1016/j.toxicon.2017.10.019

Urs NAN et al (2014) Implications of phytochemicals in snakebite management: present status and future prospective. Toxin Reviews 33(3):60-83. https://doi.org/10.3109/15569543.2013.854255

Veeresham $C$ et al (2013) In vitro and in vivo aldose reductase inhibitory activity of standardized extracts and the major constituent of Andrographis paniculata. Phytother Res 27(3):412-416. https:// doi.org/10.1002/ptr.4722 